\title{
Después de la modernidad: reflexión sobre la acción de Dios, la acción del hombre, y cómo la razón se conoce en-acción a sí misma y lo que está encima de ella"
}

\author{
María Belén Tell**
}

Recibido: 4 de Febrero de 2014 • Aprobado: 30 de Abril de 2014

\section{Resumen}

Las páginas que siguen versarán sobre los siguientes interrogantes: ¿es posible que la metafísica se constituya como un conocimiento verdadero y válido, ya que lo inmaterial no se puede "conocer" en sí mismo?; ¿qué método utilizar para ampliar los esbozados por las corrientes cartesiana, kantiana, habermasiana, así como por las vertientes humeana, positivista, empirista-lógica, genealógica y deconstructiva? ¿El conocimiento que se obtiene a través de la razón es la única vía posible para acceder al conocimiento de Dios? Y si no es así, ¿esa otra vía tiene alguna verdad y validez en cuanto método supraracional? En este contexto, incorporaremos algunos resultados de P. Ricoeur, de M. Blondel y, como eje central, ciertas cuestiones de la Suma de teología de Santo Tomás, pasando así de un análisis y estudio teórico-filosófico hacia uno poético-filosófico. Esto permitirá seguir preguntando y abriendo el escenario hacia un par de propuestas filosóficas concretas, que recapitulan lo anterior y arriban a la problemática central sugerida.

Palabras clave: Dios, acción, ser humano, razón, metafísica.

* El presente artículo corresponde a una reformulación del resultado de una investigación reflexivo-filosófica inédita, realizada en el marco del Diplomado en la Filosofía de Santo Tomás de Aquino, en Concepción-Chile en el año 2011.

** Doctora en Filosofía por la Universidad Pontificia de Salamanca, España. Institución de pertenencia: Centro de Investigación de la Universidad Santo Tomás, Bucaramanga-Colombia. Correo electrónico: filosofia8@yahoo.com 


\title{
After modernity: reflection on the action of God, the action of men, and how the reason is known in -action of itself and what is above it.
}

\begin{abstract}
The following pages will address the following questions: is it possible that metaphysics is constituted as a true and valid knowledge, since the immaterial cannot be "known" in itself?; what method to use to expand those outlined by Cartesian, Kantian and Habermasian currents, as well as by the human, positivist, empiricist logic, genealogical and deconstructive aspects? Is knowledge obtained through reason the only possible way to access the knowledge of God? And if not, does that other way has any truth and validity as super-rational method? In this context, we will include some results of P. Ricoeur, M. Blondel and, as central theme, certain questions of Summa Theologiae of Saint Thomas, thus going from a theoretical-philosophical analysis and study towards a poetic-philosophical one. This will enable to continue asking and opening the scenario towards a couple of concrete philosophical proposals, that recapitulate the foregoing and reach the central issue suggested.
\end{abstract}

Keywords: God, action, human being, reason metaphysics

\section{Après la modernité : réflexion sur l'action de Dieu, l'action de l'homme, et comment la raison se connait en action à elle-même et ce qui se trouve au dessus d'elle.}

\section{Résumé}

Les pages suivantes seront axées sur les interrogations suivantes: ¿est-il possible que la métaphysique se constitue en tant que connaissance vrai et utile, étant donné que l'immatériel ne peut être « connu » en soi même? ¿Quelle méthode utiliser pour développer les énoncés du courant cartésien, kantien, habermasien, ainsi que les domaines humeana, positiviste, empirique-logique, généalogique et dé-constructif.?

¿La connaissance qui s'obtient à travers la raison est l'unique voie possible pour accéder a la connaissance de Dieu? et si ce n'est pas ainsi, cette autre voie a-t-elle une certaine vérité et validité en tant que méthode supranationale? Dans ce contexte, nous incorporerons quelques résultats de P. Ricoeur, de M. Blondel et comme axe central, certains éléments 
de la Somme de Théologie de Saint Thomas, passant ainsi d'une analyse et étude théoricophilosophique vers une poético- philosophique. Ceci permettra de continuer à poser des questions et à ouvrir le terrain vers deux propositions philosophiques concrètes, qui récapitulent les points antérieurs et amènent à la problématique centrale suggérée.

Mots clés: Dieu, action, être humain, métaphysique.

\section{Introducción}

Los reduccionismos metodológicos moderno-contemporáneos y su imposibilidad de exceder los límites de la ciencia, así como las denuncias nietzscheanas a esta, las náuseas existencialistas y las deconstrucciones desmitificadoras de los ideales históricos controladores y carcelarios de la vida, de la salud física, psíquica y espiritual y, en definitiva, de la 'felicidad' humana; así como el auge de la economía neoliberal-capitalista y la caída de la ilustración, de los grandes relatos, de los totalitarismos y de las filosofías de la historia, que depositaban la autosalvación y el progreso indefinido de la humanidad en la ciencia y técnica modernas, en una racionalidad romántica absolutista y en una revolución proletaria marxista (Ruiz de la Peña, 1993, C. 2), dibujaron el actual panorama global definido como "mundo light", a la carta, apático, descomprometido, huidizo y virtual, en el que el horizonte último de la vida humana, de la cultura y de las sociedades residen en el consumo veleidoso, en la compra-venta eficaz, y en la oscilación sin respiro de las finanzas comerciales que van y vienen fugazmente a nivel planetario. Pareciera que en la modernidad fue tan profunda la apoyatura del ser humano sobre sí mismo, que después los individuos quedaron atrapados, viciados y asfixiados de sí, alienados y enajenados en sus oficios, capturados ${ }^{1}$ dentro de sus propios solipsismos inmanentes, que no dejan lugar ni siquiera a la nada, puesto que la 'nada' sería ya una oportunidad para otra cosa, o para algo más, o bien alternativa para una búsqueda verdaderamente genuina y auténtica.

Sin ánimo de ser alarmistas, y lejos de caer en un pesimismo sin retorno, es evidente que transitamos un mundo tecnificado, desencantado, materialista, en el que descubrimos el genoma humano, pero en el que todavía nos cuesta responder a las preguntas de qué buscamos, quiénes somos, hacia dónde vamos.

1 Según Agamben, "[1]lamaré literalmente dispositivo cualquier cosa que tenga de algún modo la capacidad de capturar, orientar, determinar, interceptar, modelar, controlar y asegurar los gestos, las conductas, las opiniones y los discursos de los seres vivientes" (Agamben, 2005, pp. 4, 5) 
Por lo tanto, y en este sentido, nos cuestionamos, en suma, qué es capaz de buscar hoy el ser humano, más allá de toda máscara cultural, de toda moda, ideología o artificio. En tal contexto, entonces, pretendemos ahondar en este interrogante profundizando hasta el fondo las exigencias que manifiesta nuestra existencia: ¿Sí o no, la vida humana tiene un sentido y el hombre un destino? Yo actúo, pero sin siquiera saber qué es la acción, sin haber deseado vivir, sin conocer exactamente ni quién soy, ni siquiera si soy. Oigo decir que esta apariencia de ser que se agita en mí, que estas acciones livianas y efímeras como sombras, llevan en sí una responsabilidad eternamente pesada, y que ni siquiera a precio de sangre puedo comprar la nada porque para mí esta no existe más: ¡yo estaría entonces condenado a la vida, condenado a la muerte, condenado a la eternidad! [Pero] ¿cómo y con qué derecho, si yo no lo he sabido ni querido?

[...] Si hay algo que ver, tengo necesidad de verlo. Sabré quizás si, sí o no, este fantasma que soy para mí-mismo, con este universo que llevo en mi mirada, con la ciencia y su magia, con el extraño sueño de la conciencia, tiene alguna solidez. Descubriré sin duda lo que se oculta en mis actos, en ese fondo último donde, sin mí [y] pese a mí, sufro y me adhiero al ser. Yo sabré si tengo un conocimiento y una voluntad suficientes del presente y del futuro, para no sentir nunca su tiranía, sean como ellos fueren.

El problema es inevitable; el hombre lo resuelve inevitablemente; y esta solución, correcta o falsa, pero voluntaria al mismo tiempo que necesaria, cada uno la lleva en sus acciones. He aquí por lo que hay que estudiar la acción: la significación misma de la palabra y la riqueza de su contenido se desplegarán poco a poco. Es bueno proponer al hombre todas las exigencias de la vida, toda la plenitud oculta en sus obras, para fortalecer en él el coraje de actuar con la fuerza de afirmar y de creer. (Blondel, 1973, § VII, VIII.)

Procuramos recuperar, así, a través de estas perennes palabras del filósofo M. Blondel, la importancia, necesidad, peso y desafío que implica existir como y actuar como ser humano, a diferencia del significado que pareciera tener la acción en nuestro ambiente contemporáneo, ya que no sería más que 'movimiento', cambio, producción o 'espectáculo', en la medida en que se constituye en la actuación de un actor que huye de su lugar como autor (cf. Foucault, 1990, pp. 
$16,17,29)$ y deja de ser responsable de sus actos y, en consecuencia, de su propia identidad.

Cuando la reflexión versa sobre el ser humano y sobre Dios no hay tema profundo que pueda dejarse de lado. Si hablamos del ser humano, de Dios y de la acción no pueden olvidarse temas tales como el sentido, el destino, el peso de responsabilidad que reside en las acciones y el fondo último que estas también confiesan. De este modo, Blondel nos hace patentes tales problemáticas, tan olvidadas en nuestros días, para poder realizar nosotros mismos - y a la luz de los escritos tomasinos - un escrutinio válido y así ser capaces de volver a religar, a través del problema de la acción, los dilemas de la identidad humana - en cuanto son una afirmación ontológica de la realidad - y de la fe.

Tomaremos, entonces, como punto de partida y eje de nuestra reflexión, algunas cuestiones de la Suma de teología de Santo Tomás:

"En definitiva, durante la vida terrena, ni el entendimiento posible ni el agente pueden conocer lo inmaterial en sí mismo" (I, C.88 a.1).

"Por las cosas materiales no podemos conocer perfectamente las sustancias inmateriales" (I, C.88 a.2).

"Dios no es lo primero que conocemos, sino que llegamos a su conocimiento por medio de las criaturas [...]. Lo primero que nosotros entendemos en el estado terreno de nuestra vida es la esencia de lo material, que es el objeto de nuestro entendimiento [...]" (I, C.88 a.3).

En torno a estos juicios se nos presentan varias inquietudes; sin embargo, profundizaremos en solo tres: en primer lugar, ¿es posible la metafísica como conocimiento verdadero y válido, ya que lo inmaterial no se puede 'conocer' en sí mismo? En segunda instancia, ¿qué método utilizar para complementar los esbozados por las corrientes cartesiana, kantiana, habermasiana, así como por las vertientes humeana, positivista, empirista-lógica, genealógica y deconstructiva? Y, ulteriormente, ¿el conocimiento a través de la razón es la única vía posible para acceder al conocimiento de Dios? Y si no es así, ¿esa otra vía tiene alguna verdad y validez en cuanto método suprarracional? 


\section{Posibilidad de la metafísica y de la afirmación de sí mismo, a través de la acción}

Puntualicemos, ante todo, que partimos desde este punto, puesto que la tradición moderna y sus consecuencias en todo ámbito constituyen esa sombra o aliento subrepticio que aún hoy se respira; esto es contrario, ciertamente, a la experiencia que Tomás de Aquino tuvo en el siglo XIII, ya que su contexto cultural y el aire que inspiraban al conocimiento y a la acción eran definitivamente otros. Asimismo, cabe señalar que los puntos de partida de Santo Tomás y los de la Modernidad y Tardomodernidad que hoy transitamos son bien disímiles, dado que el Aquinate parte de las cosas, de la realidad — creada - , para complementarla con la realidad revelada, como luego veremos. De esta forma, el inicio de la reflexión en Santo Tomás es el mundo, las cosas, aquella "[a]tracción que la realidad suscita en la razón” (Cf. Molteni, 2009, § 10.). Como corolario se tiene que esta razón constituirá el receptáculo activo de dicha realidad.

Por el contrario, el giro copernicano cognoscitivo y epistemológico que emprendió la modernidad consistió en instaurar como punto de partida del conocimiento y de la realidad al pensamiento, al entendimiento o razón, como una facultad que produce conocimientos claros y distintos, que juzga y construye según ciertos principios a priori- la verdad de la realidad. Así, sobrevino el criterio de demarcación kantiano, a través de la introducción del concepto de juicios sintéticos a priori. Con estos, este autor pretendía demostrar y consolidar, en sus dos síntesis de la sensibilidad y del entendimiento, un patrón de conocimiento verdadero del universo, como cientificidad analítica y experimental. Puesto que, en definitiva, en la Crítica de la razón pura se intentó de tal modo 'purificar' a la razón, al punto de encontrar en esta el fundamento, el método y el criterio último para poder conocer la verdad cierta de las cosas, y, en alguna medida, autopostularla como "modelo metafísico" sin más. No obstante, en lugar de brindar un nuevo método gnoseológico-metafísico para la filosofía, se terminó erigiendo a las ciencias particulares (lógica, matemática, física) como criterio primero y definitivo de verdad y de la validez de la realidad. En este contexto, el ser humano se proclamó juez y señor de los fenómenos del universo, en la medida en que se autodefinió como una res cogitans (cf. Gilson, 1935, pp. 9ss, 78ss.)

Empero, las afirmaciones de Santo Tomás parecieran coincidir con estas tesis en algún aspecto, dado que sostiene que "[...] ni el entendimiento posible ni el agente pueden conocer lo inmaterial en sí mismo” y, sigue, “[...] lo primero que nosotros entendemos en el estado terreno de nuestra vida es la esencia de lo 
material, que es el objeto de nuestro entendimiento [...]". Pues bien, en la crítica kantiana, lo inmaterial, que fue siempre el objeto de la metafísica, aparece representado por las nociones de Dios, de mundo como totalidad y de alma, pues estos representan noúmenos o cosas en sí en contrapartida a los fenómenos que sí se pueden conocer. ${ }^{2}$ El resultado al que tales conclusiones kantianas, así como varias de las posteriores corrientes filosóficas contemporáneas nos arrojaron, fue al de un dictamen soberano en el que Dios, el alma y el mundo son meramente ideas regulativas de la razón, que esta utiliza para regular y ordenar la existencia humana y a la sociedad, que solo pueden pensarse, pero no conocerse, porque solo se puede conocer el fenómeno científico.

En otras palabras, los dilemas históricos clave de la filosofía y de la búsqueda humana quedaron reducidos a meras ideas vacías y sin contacto de ningún tipo con la hondura de la existencia. Por lo tanto, y en este sentido, hay un solo paso entre esta herencia ilustrada, traducida en un solipsismo eidético-trascendental, junto a su reverso panteísta del absoluto hegeliano, y el profeta nietzscheano Zaratustra, quien anuncia que Dios ha muerto. En consecuencia, los problemas que siembra semejante legado son múltiples, pero dos de ellos son los que más nos interesan, a saber la posibilidad de reestablecer a la metafísica y de 'llegar' a Dios, así como a la existencia humana, al conocimiento y a la afirmación de sí misma.

En efecto, si el énfasis que la reflexión cuasimetafísica moderno-kantiana puso en las representaciones, ideas y criterios a priori de la razón, o, en síntesis, en las sensaciones, nos arrojó a la orilla de la muerte de Dios, nos urge, entonces, iniciar el recorrido desde otro lugar en el que puedan encontrarse y armonizarse, por qué no, la noción de realidad comprendida desde Santo Tomás y Aristóteles y la de razón como es entendida por la tradición clásica y moderna. Por ende, cabe cuestionarse desde dónde se debe empezar para llegar a un posible conocimiento auténtico de uno mismo y de Dios.

Por tanto, consideramos que son dos las vías filosóficas que podrían reconducirnos en el camino hacia la cuestión de Dios así como hacia la propia existencia. Creemos que dichas vías, que requieren ser recuperadas y ampliadas para llegar a la cuestión de Dios, son, por una parte, la vía antropológica y, por otra, la gnoseológica-epistemológica. Entre estas vías se funda la posibilidad de una metafísica ${ }^{3}$ capaz de asumir la historia, el hecho de la ciencia-técnica, así como

2 Luego veremos que en Santo Tomás sí es posible conocer a Dios, al alma y al mundo, pero consideraremos con detalle mediante qué vía metodológica esto se logra.

3 Utilizamos el término metafísica en el sentido de fundamento, de pregunta y de búsqueda-comprensión última con un vínculo con el mundo, consigo mismo y con Dios o el 
un criterio de verdad que reactive el concepto de relación, en este caso entre la realidad personal, el reconocimiento de la dimensión trascendente - o la huella de Dios en ella - y la realidad externa. Esto permite integrar también los distintos niveles de conocimiento de la metafísica.

En dicho itinerario expositivo, pues, incorporaremos algunos alcances de P. Ricoeur y de M. Blondel, como ya venimos haciendo y, como eje central, ciertas cuestiones de la Suma de teología de Santo Tomás, como también estamos escrutando, pasando así de un análisis y estudio teórico-filosófico hacia un rodeo poético-filosófico, para continuar preguntándonos y abriendo el escenario hacia un par de propuestas filosóficas concretas, que recapitulan lo anterior y arriban a la problemática central sugerida.

\subsection{En torno a la receptividad-pasividad}

En tal contexto, y para dar respuesta a una de las preguntas precedentes, consideramos que un punto de partida posible se puede hallar en el texto de Blondel ya citado, que además coincide con este pasaje del filósofo contemporáneo P. Ricoeur:

Esta existencia bruta yo no la he querido, han sido otros los que la quisieron; peor aún, ellos no la han querido exactamente; pues sé bien que se ha asumido una responsabilidad que no fue medida, pues se ejercía en la proximidad de potencias imposibles de calcular; se trata de una monstruosa confabulación de azar, de instinto y de la libertad del otro lo que me ha arrojado a esta orilla. (Ricoeur, 1986b, pp. 468-469) ${ }^{4}$

En este extracto aparece una reflexión medular, además de las mencionadas anteriormente, como la pregunta por la existencia y su sentido, así como por la responsabilidad y la plenitud oculta en las obras humanas, hay algo nuevo que asoma y que no estaba de forma explícita en la meditación blondeliana: “[...] la libertad del otro $[\ldots]^{\prime \prime}$. Vale decir que, a diferencia del principio moderno racional

\footnotetext{
Absoluto. Por eso, es que no aparecerán disociados los conceptos de metafísica y de relación. Podría agregarse que la metafísica constituiría, así, un tercer grado de relación, esto es una relación última respecto de las tres instancias recién mencionadas.

4 Cabe destacar que optamos por citar este pasaje en su traducción al castellano, dado que esta trasluce correctamente el significado de las palabras del autor, hasta en su sentido poético.

5 Aquí se pone en evidencia la paradoja de la libertad, ya que la libertad personal es originariamente receptivo-pasiva respecto de la libertad de un otro respectivamente.
} 
humano activo, universal y epistémico, ahistórico y desencarnado, aparece aquí el drama de la existencia como una pasividad, como una pasividad originaria, que es consecuencia de la libertad de un otro (cf. Tell, 2008, pp. 169-184).

Si bien la herencia moderna y tardomoderna nos legó una lógica 'racional' vacía, autofundante y ególatra, una racionalidad burocratizada y sumida en una rational choice, teniendo que venir en su rescate la Escuela de Frankfurt de posguerra, el horizonte de precomprensión hermenéutico de Gadamer y el Dasein heideggeriano, el desarrollo en los "márgenes de la escritura" al mejor estilo derridiano, la apuesta a la huida total de esa racionalidad y sujeto moderno epistémico a un no lugar o no sujeto y en ausencia de cualquier fundamento; nosotros proponemos frente a semejante panorama, en cambio, repensar y discernir hasta el fondo estas exigencias pasivo-activas propias de la existencia humana, por la razón de ser en unidad corpóreo-espiritual integrado de inteligencia, afectos y de voluntad-acción. Estos tres elementos de la existencia humano son los que, a través de la acción y de la pasividad-receptividad, encontrarán su cause en las reflexiones suscitadas por Santo Tomás, Blondel y Ricoeur.

Repensando a fondo, entonces, estos problemas e incorporando aspectos que la tradición filosófica dejó de lado, postulamos aquí una posible recuperación del fundamento y de una gnoseología-metafísica y del ser humano como aquel ser capaz de afirmar y de creer. La posibilidad concreta de la metafísica se reencontraría, así, a través del retorno a las cosas mismas o a la realidad que desborda, que enriquece y abre la 'anchura' y los límites de la razón humana, a través de las duplicidades conceptuales centrales de pasividad/receptividad y de potencialidad-actividad/iniciativa (cf. Ricoeur, 1986a, p. 289ss). Cuando se descubre la realidad en cuanto una, verdadera, buena y bella, se reconoce la razón y la acción, la receptividad y el acto, la pasividad y la actividad. En la realidad misma, si uno la sabe contemplar con detenimiento, se puede llegar a vislumbrar que será esta la que otorgue el Camino-método y el contenido-Verdad frente a cualquier exigencia de la existencia, cognitiva o volitiva respectivamente.

De esta manera, el criterio que posibilitaría la metafísica y la afirmación de sí mismo sería esta receptividad-acción "enraizada” en la realidad, esto es la que estimula y permite que el ser humano se con-forme, se satisfaga, en la medida en que es la realidad la que le devuelve la forma que busca y que exige la existencia como unidad manifestada en cada acción. Si bien la condición humana reclama un sentido, un origen y un fin, así como una inquietud, una actividad que no pareciera saciarse con ninguna acción, será la realidad, la viva y activa la que le donará un cause, una respuesta y una presencia a tales pretensiones. 
El método que formulamos para recuperar la pregunta por la metafísica y por la identidad del ser humano, así como el momento o el lugar en los que ambas se encuentran y el vínculo entre una y otra, consiste en esta vía relacionalrealista. Dicho método implica la apuesta por una realidad viva, por una toma de conciencia del propio límite humano y del "[...] finito deseo infinito de Infinito" (Tell, 2003, pp. 45-52), que la persona alberga en su interior y que la desborda. De la misma manera, implica reconocer las pasividades-receptividades propias de la condición humana, así como el tomar conciencia de que el anhelo de la acción no se sacia con nada finito y limitado, y que la realidad ${ }^{6}$ es la medida (Santo Tomás, 1996, pp. 62, 65-68), y posible respuesta, de esta incansable - y dramática por momentos-, búsqueda relacional humana a través de la inteligencia ${ }^{7}$ y de la voluntad.

La realidad es la garantía y el ser de las cosas, es la condición del conocer y de todo lo demás y no viceversa “'Las cosas son' [...] [es] la primera de todas [las evidencias], que conduce, por una parte, a la ciencia, y, por otra, a la metafísica; es este, entonces, un método sano para comenzar" (Gilson, 1935, p. 86). Según tales juicios, podría sugerirse que la tradición moderna hubiera 'enfermado' a la razón, lo que la forzó a no respetar sus propias exigencias de correspondencia y conformidad relacional pasivo-activa con las cosas mismas.

¿Qué tendrá que ver este método realista, que posibilita la metafísica, con el ser humano y su posible afirmación de sí? Diremos que todo está íntimamente vinculado, porque, en primer lugar, el ser humano no conoce solo ideas - "la idea de caballo no es el objeto de nuestro conocimiento" (Molteni, 2009, pto. 12.$1^{\circ}$ parte) - , ni tampoco es la razón ni el sentido los que conocen, sino que es el ser humano total, su existencia completa y concreta la que conoce a través de ambos. De esta manera, la posibilidad de la metafísica, el sentido de la existencia humana y el criterio de verdad constituirían así un vínculo tripartito, entendidos como verdad-relacional-trialógica imposible de separar. Es a causa de la presencia de la realidad, que se impone y atrae a la razón, que el ser humano, como unidad

6 Cf. "En el realismo la fe, la razón, la crítica, el análisis, la observación, el experimento, son vías y métodos por igual legítimos, que nos proporcionan conocimientos verdaderos de la realidad, cuando se adaptan convenientemente a las estructuras ónticas del objeto estudiado." (García Morente, 1996, p. 76.)

7 Si bien no ignoramos las disquisiciones y distinciones etimológicas y conceptuales de los términos inteligencia, entendimiento y razón-racionalidad, en este escrito decidimos emplearlos como vocablos equivalentes, más allá de sus diferencias de origen y uso en los diversos autores y épocas filosóficas. 
existente, es capaz de conocer - recibir la realidad y luego operar en ella - y de abrir sus sentidos y razón hacia una dimensión más amplia que lo excede.

En efecto, dicha relación trialógica activa entre fundamento, ser humano y verdad implicaría un vínculo "existencial", entendido como conocimiento afectivo e integral del individuo y en la medida en que "[...] la cosa que está fuera del alma mueve al entendimiento y la cosa entendida al apetito y éste, a su vez, conduce a la cosa de la que empezó el movimiento" (Molteni, 2009, pto. 17.-1 ${ }^{\circ}$ parte). Así pues, se constata de qué manera esta conexión y contacto íntimo y afectivo del individuo con la realidad, a través de su expectación pasivo-receptiva y de su acción u operación, le permite conocer la realidad y buscar su fundamento, así como ahondar en la propia experiencia y sentido último de su vida.

Si uno de los embates de la modernidad estuvo en la cerrazón enajenante sobre la persona misma, en la escisión, en el quiebre, en la separación y huida de la realidad, como 'psicosis epistemológica' — con sus lamentables consecuencias en todo ámbito-; la vía posible y prometedora que se abre aquí, mediante el método realista-relacional, invita a unir, a armonizar, a integrar y valorar todos los elementos con los que se cuenta sin dejar nada de lado. Por lo tanto, las cosas son, luego las conozco, de manera que una identidad personal, flexible y 'confiada' es capaz de relacionarse y adecuarse a la realidad evidente llegando, así, al objeto de conocimiento que está en ella.

La razón se descubre en la acción, en la relación con la realidad: uno conoce porque la realidad acontece, se conoce lo que está en acción. Es la realidad la que ilumina la razón y los sentidos, y su conocimiento de es posible en la medida en que la razón se someta a la exigencia de la experiencia, haciendo justicia con la interpelación de la razón misma, que implica la adecuación y correspondencia con la anchura de la realidad. Sin embargo, resta vincular, mediante este método realista propuesto, la dinámica de la razón - en cuanto acción humana existencial - a la fe, comprendida como invitación y propuesta de Dios que permite, así, dilatar la razón y lograr una metafísica realista-relacional-existencial. 


\section{Diálogo y complementariedad entre la razón (acción del hombre) y la fe (acción de Dios)}

\subsection{La acción del hombre}

En primera medida, recordemos que, según Aristóteles, el movimiento de la ousía se define como el tránsito de la potencia al acto, todas las cosas son mezcla de potencia y acto, de lo menos perfecto a lo más perfecto, tendiendo hacia su telos. Por lo tanto, todas las cosas apetecen ser y ser en acto, y todo ente al tener esse posee fundamento para tender hacia su fin, así como para ser apetecido. Todo ente procura, entonces, conservarse y sustentarse en el ser, perfeccionando su forma (cf. Santo Tomás, 2001, I, C. 105 a.3). En cada grado de perfección de los seres de la naturaleza será más perfecta la ousía que esté en acto respecto de su esencia y, en una dimensión más específica, respecto de su forma. Pues bien, dicho esto, concluyamos que para que el ser humano se dirija a su telos en un crecimiento paulatino en sus grados de perfección, tendrá que poner en acto su forma, o sea su razón o entendimiento. Integrando la visión tomista en este punto, diremos que no será cualquier razón la que se actualice, sino una razón o racionalidad existencial y conectada - apetitivo, afectivo, estético-poéticamente ${ }^{8}$ - con la realidad.

En consecuencia, los sentidos y la razón humana se mueven existencialmente, como ya se mencionó, no alienados o negados, sino integrados al resto de las potencias volitivas y afectivas, y es por esto que puede la razón conectarse con la realidad y pretender, así, conocerla. El conocer, entender y razonar, el desear y el querer son operaciones que buscan, que pretenden agotar y encontrar aquel objeto anhelado, el cual pareciera escaparse o alejarse, cada vez más, a los ojos de las facultades y potencias humanas. Asimismo, reiteramos que estas pretensiones y exigencias de la existencia se relacionan con el telos, se dirigen al alcance de la perfección y permiten colocar en acto al ser de la persona, mediante la actividad de las potencias del individuo, especialmente de la razón en cuanto su forma.

En el individuo existe una amistad relacional entre el ser y el conocer. Por tanto, el conocimiento humano nace de un acontecimiento de la realidad, nace de la acción de la realidad y, en consecuencia de la razón, en una primera instancia. Luego que la razón conoce el objeto, en un segundo momento, "nuestro

8 La función poética o discurso poético como manifestación de la belleza “[...] se refiere a nuestras múltiples maneras de pertenecer al mundo antes que nos opongamos las cosas a título de 'objetos' que enfrentan a un 'sujeto'" (Ricoeur, 1994, p. 105). 
entendimiento se conoce a sí mismo no por su esencia, sino por su acto" (Santo Tomás, 2001, I, C.87 a.1). Por consiguiente, es gracias a la acción del entendimiento que este se conoce y toma conciencia de sí mismo y llega, así, a otro de los temas centrales del presente trabajo.

En efecto, toda la realidad está en movimiento y en acción en pro de su consecución del fin perfecto intrínseco a cada naturaleza. De este modo, el ser humano, en la medida en que es un existente que conoce, razona, desea y decide, es un ser en recepción-acción-relación, pero la conciencia de dichas operaciones se da también gracias al acontecimiento vivo de la realidad. Por lo tanto, el punto de partida de todo conocimiento y de toda reflexión será este: la realidad siendo, estando presente y actuando; y el ser humano inserto en ella como pasivo 'receptor' de semejante espectáculo, pero también como individuo capaz de conocer-relacionalmente esa realidad $y$ de abrirse a su fundamento último. Ya que el hombre, a diferencia del resto de los seres, posee un fin último muy superior al de los demás, este fin no solo será perseguido naturalmente por la condición humana, sino que será además 'puesto' en acto en la historia, porque el deseo de este fin se adecuará o corresponderá con la presencia activa y real del mismo, ya que es el propio fin el que se encarna en la historia para que el ser humano pueda afirmarse y creer en este.

En suma, lo primero que es conocido por el entendimiento humano es la naturaleza de lo material, lo segundo es el mismo acto por el que es conocido el objeto y cuya perfección consiste en entender. En este sentido, los objetos se conocen antes que los actos, y estos antes que las potencias (cf. Santo Tomás, 2001, I, C.87 a.3); es porque se padece la realidad que se puede, luego, operativamente conocerla. Lo interesante en el ser humano, pues, es que toda acción está sujeta siempre a un doble aspecto, a saber a la pasividad y a la receptividad, dado que todo individuo recibe pasivamente su ser, en cuanto don, con sus potencias y existenciarios $^{9}$ antropológicos determinados en vista a un fin. Y luego, mediante el paulatino crecimiento, desarrollo y aprendizaje, será capaz de ir poniendo en acto sus capacidades. De este modo, la acción en el hombre es paradójica, al igual que el resto de su condición, ya que no puede comprenderse cabalmente su acción sin su reverso originario de la pasividad y receptividad. Este aspecto doble y mixto del ser humano, que es finito pero anhela infinitud, que recibe y padece todo lo que es pero pretende ser en acto y llegar hacia su fin último, nos aporta la distinción clave

9 Es preciso señalar que el término existenciario lo empleamos en un sentido fenomenológico, referido a las estructuras constitutivas en tensión, receptivo-originarias, vacías y formales del individuo. 
e inédita respecto de la acción del hombre, a diferencia de la acción divina que también entra en juego en la existencia humana (cf. Ricoeur, 1960, pp. 156, 157).

Asimismo, la racionalidad, la razón existencial y relacional, conectada apetitiva, afectiva, estético-poéticamente en acción, recibe primeramente la realidad y posteriormente actúa con ella. Aquí se encuentra el mismo el criterio de verdad: en este sí, en esta correspondencia y adecuación entre la razón - en cuanto unidad existencial humana - y la realidad. No obstante, la tendencia natural existencial nunca deja de buscar la verdad total, el bien perfecto y la suma belleza - propiedades trascendentales del ser - como fin último de la vida. ¿Qué le corresponde y le conviene, entonces, a la condición humana como fin último y plenitud de su existencia? ¿Dónde coinciden pasividad-contemplación y acto? ¿Dónde se encuentra la integración tan deseada? ¿Qué permanece oculto, en cuanto misterio, en la realidad que brilla y resplandece, pero que se esconde y no se deja entrever del todo? En la medida en que el acontecer del ser revela el misterio, habrá que permanecer frente a la realidad para escuchar, en el silencio, su voz.

Se vislumbra que la existencia humana continúa todavía a tientas, a oscuras, en este plano estrictamente humano y natural, pudiendo sí reconocer la existencia de un Otro Infinito, pero sin poder aún hallar plenamente, por esta sola vía racional, aquel objeto que le permita afirmarse a sí misma en la realidad, así como unirse al objeto buscado, mediante una experiencia metafísica existencial. Empero, la razón residirá precisa y, paradójicamente, en esta incapacidad o debilidad y pasividad humanas es donde Dios saldrá al encuentro del hombre, ya que el dios de Santo Tomás dista mucho del de Aristóteles y del de la tradición grecomoderna clásica. La razón es que en el Aquinate, Dios coincide con el de la Revelación judeocristiana, siendo un Dios que es amén y roca firme, en el que la vida se apoya, siendo un Dios que acontece en la historia y que busca al hombre para responder a todas las exigencias que Él mismo ha instaurado en su naturaleza. A diferencia del dios de los filósofos griegos, el cual no llegaba nunca al hombre que, a su vez, no podía jamás acceder a aquel; esto propiciaba una brecha entre el anhelo de la persona y aquel 'objeto' y ciencia buscada pero nunca alcanzada (cf. Aubenque, 1966, pp. 67- 68, 368-411).

El dios de Tomás es un dios vivo, que se encarna en la realidad y vive, acompaña al ser humano en cada instante, fundamenta el universo como causa y principio trascendente, pero, asimismo, actúa, acontece en el presente y está encarnado en el co-razón $n^{10}$ de la experiencia y vida humanas. Cuando se comien-

10 Concepto de co-razón (con la razón) se define de esta manera: es un criterio con el que la razón juzga, compara y desea todo, dentro de sí misma; hace referencia a los primeros 
za a descubrir, a conocer y reconocer las exigencias propias de la existencia, en orden a alcanzar el anhelo de verdad y bien en relación y correspondencia con la realidad, con las cosas mismas, se llega a otro aspecto importantísimo sin el cual la razón quedaría coja y ya no podría seguir avanzando: este elemento capital es la dimensión trascendente y religiosa de la racionalidad existencial humana ${ }^{11}$.

\subsection{La acción de Dios}

Retomando el vínculo tripartito entre existencia humana, realidad y Dios, se advierte que la acción propia de Dios solo se puede ver, juzgar y aceptar desde aquella experiencia plena y dinámica de la fe. El objeto de la fe es Dios y lo que Dios ha dicho, dice y actúa, en la medida en que esto conforma una presencia eficaz en el mundo. Sin embargo, el objeto de la fe no es el mismo que el objeto de la razón, puesto que la desborda, va más allá de esta; sin embargo, esta le brinda condiciones para ver y comprender más de lo que ella por sí misma es capaz. Lo que, asimismo, desborda a la razón y excede su espera es el hecho imprevisto, impensado e imprevisible del acontecimiento o revelación de Dios en la historia, y sobre todo hecho carne en Jesucristo (cf. Molteni, 2009, pto. 3.-2 ${ }^{\circ}$ parte). Que Dios mismo asuma la condición humana, mostrándole y don-ándole así lo que buscaba $^{12}$ y pretendía la naturaleza del hombre, y a su vez elevándola a un plano último alcanzable para la persona, convierten a este hecho en el pilar principal de la realidad histórica.

La acción de Dios respecto de la creación y del hombre ha estado siempre ocurriendo. Como afirma Santo Tomás: “[...] Dios está en todas las cosas íntimamente[...], está en todas las cosas dándoles ser, virtud y acción [...]" (Santo Tomás, 2001, I, C.8 a.1, 2). No obstante, en el concreto y divino acontecimiento de la encarnación, en el que Cristo, como mediador, oficia de puente de reconciliación

principios que permiten que la persona se quede con lo que le 'conviene', con todo lo bueno que acontece en la realidad (cf. Molteni, 2009).

11 "Lo que de Dios puede comprender la sola razón humana, también precisa la revelación divina, ya que, con la sola razón humana, la verdad de Dios sería conocida por pocos, después de muchos análisis y con resultados plagados de errores" (Molteni, 2009, pto. 21.- $1^{\circ}$ parte).

12 El ser humano ya no necesita buscar, anhelar inacabadamente - eros -, sino que "es capaz" de gozar - producto de un regalo-, desde ahora, la vivencia y despliegue del ágape. A través de la encarnación, el eros filosófico y el ágape de Dios donándose se encuentran en la historia en un inefable diálogo amistoso de eternidad, que desborda cualquier especulación, ley y cálculo humano. 
entre el Padre y la criatura humana, la acción de Dios cobra dimensiones insospechadas, porque Dios está presente y hecho 'hombre' entre los hombres. Dios, encarnado, constituye el camino y el fin, el sentido y el destino de todo cuanto el ser humano puede desear (cf. Molteni, 2009, pto. 7.-2 ${ }^{\circ}$ parte), pero también supera este objeto, dado que Dios al quitarse el velo y darse a conocer, excede y enriquece la propia condición humana como capax Dei, que todo individuo alberga en su naturaleza. La vivencia de la trascendencia implica continuar 'tocando' hoy la humanidad de Cristo, puesto que palpar su humanidad es degustar su divinidad.

La felicidad, como fin último al que el ser humano está llamado, se colma y agota con y en la humanidad de Cristo, porque en Él el camino y el destinocontenido coinciden, ya que Él encarna la vida, la verdad, el bien, la belleza y, además, se postula como el método efectivo de plenitud. Si "el destino ya está en el camino", Jesucristo es la respuesta definitiva en la realidad de la historia frente a las pretensiones de la razón y de la fe. Si, como sostiene el Aquinate, “[...] vivir principalmente consiste en sentir y conocer" (I, C.18 a.2), y la vida se da en grado sumo en Dios, hemos experimentado 'realmente' la vida en sí misma a través de la vivencia de Cristo, porque todavía podemos sentir y conocer aún hoy su acción en el mundo y en cada persona. Esta vida es posible porque "en Dios se da una potencia activa, siendo Dios principio activo y acto puro, absoluta y universalmente perfecto" (Santo Tomás, 2001, I, C.25 a.1). Por lo mismo, esta potencia activa y el poder de Dios son infinitos y omnipotentes, no restándole, asimismo, ni un ápice de libertad a su acción, porque "[...] Dios puede hacer absolutamente cosas distintas a las que hace" (Santo Tomás, 2001, I, C.25 a.5).

En esta libertad suma, entonces, Dios elije revelarse y, aún más, donar por amor a su Hijo hasta el punto de permitir el sacrificio de su vida en el madero de la cruz, para redención y plenitud del hombre. La acción de Dios en Cristo permite la consumación de la realidad, ya que a través de la experiencia de Él, el ser humano - y su racionalidad - ya no conoce a tientas, no sabiendo qué esperar, sino que ve, siente, experimenta y goza de la realidad consumada como signo, en un quien, en una identidad única que irradia todo aquello que el hombre anhela vivenciar. Jesucristo viene a ser la consumación de la realidad y del método, porque orienta, encauza y colma toda expectación humana sensible, racional y afectiva.

Podemos decir que aquello que perseguíamos en el punto anterior (la posibilidad de acceso a una metafísica y a la afirmación de sí-mismo, a través de la receptividad-pasividad-acción) podría resolverse en esta instancia, en un nombre, en una persona que se vislumbra como intersección entre lo humano y divino, entre la acción y padecimiento hasta el extremo en su 'pasión', en el universal 
hecho concreto y carne en la historia. Si en el plano filosófico de la razón, el conocimiento, el afecto y la voluntad humana quedaban como meros proyectos y promesas inacabadas, en el acontecimiento de Jesucristo, estos aspectos cobran verdadera y plena realidad y una actualidad no solo potencial sino real. La posibilidad concreta de la metafísica y de la afirmación de la existencia humana hasta el fondo, atendiendo a todas ${ }^{13}$ sus exigencias, se consuman en la mirada y experiencia de fe de aquel "[...] que puede llevar al acto toda potencia pasiva" (Santo Tomás, 2001, I, C.105 a.1).

La felicidad, entendida como acceso y plenitud del fin al que tienden la razón, la voluntad y los afectos humanos, se concentra y consuma en Jesucristo como núcleo y centro afectivo, que atrae la condición humana hacia su alegría metafísica existencial. Este proceso se asegura con la respuesta de fe del individuo, comprendido como gracia que perfecciona y salva la razón y la naturaleza humanas. Todo aquello que aguarda inacabado e inconcluso en el plano natural y racional espera su respuesta profunda y acabada en otro plano mayor y sobrenatural, que satisface y eleva la finitud del hombre.

La acción de Dios mueve y atrae a la persona hacia sí misma y hacia Él, y esto posibilita la afirmación de la criatura así como su plenitud y la oportunidad de meditar en torno al fundamento de lo real. Por eso, es solo a través de esta acción divina que se consuma y responde, presente y constantemente, a las exigencias existenciales del hombre. Y la fe es el consiguiente reconocimiento libre, crítico y sistemático de dicha experiencia vivida, lo que implica el abandono de la existencia adulta - en cuanto unidad de razón, voluntad y afectos-, en el amor y voluntad de ese Otro que reclama, llama y permanece.

La felicidad se entiende, pues, como esa actitud niña - no infantil - que el adulto manifiesta al reposar, descansar y entregar sus potencias para que la acción divina, pura en acto, las perfeccione y conduzca hacia una realización única e irrepetible. La vivencia, asunción y aceptación de la realidad mediante la fe es la forma, plenamente adulta, a través de la cual el hombre puede experimentar la felicidad que demanda su condición humana. La razón de esto es que el adulto, al hacerse "como un niño", recobra esa actitud de abandono y relación directa y afectiva, que va perdiendo a medida que crece y que la razón nubla, muchas veces, al postularse esta como mero cálculo, demostración y experimento manipulable científicamente. Si la sensación, la razón, la voluntad, los afectos y la

13 Cabe puntualizar que la metafísica y la afirmación de sí mismo, tendrían dos posibles etapas: la primera en una instancia natural, en tanto búsqueda y anhelo humano, y la segunda en cuanto don-ación de Dios al hombre. 
existencia humana como tales no tr-ascienden - valga el juego de palabras - , no ascienden hacia su origen y fin, no encontrarán nada que pueda conformar su pretensión. La trascendencia de la existencia a través de la fe implica la experiencia de una niñez plenamente vivida con todas las potencias adultas desarrolladas y al servicio de quien las ha donado.

El método de la fe permite, entonces, religarse, confiar en una persona, en un 'tú' que cautiva, que atrae y testimonia la plenitud de la vida, y que se identifica con esta hasta el extremo. La adultez del ser humano coincide con la consumación de la vivencia de una 'niñez' lúcida, conciente y libre, entregada a la verdad y bien de una persona. Es este diálogo y encuentro el que perfecciona, salva y plenifica la experiencia y existencia humanas en su totalidad, porque cambia y modifica la vida al generar una novedad en ella. Puesto que acontece lo divino en lo humano, dilatando la razón y la mirada hacia un horizonte más amplio y 'adecuado' para los anhelos profundos, que las mismas acciones humanas reclaman en cada acto. La experiencia de Cristo, asimismo, es también anticipo y signo de la felicidad última o salvación final y escatológica. Esto es debido a que la fe continúa la ruta que la razón le deja, pero el deseo queda encendido por este signo anticipado, pero no gozado totalmente, siendo este que la condición humana busca y anhela permanecer en dicha presencia, que será manifestada y realizada al final de los tiempos.

Concluyamos este apartado afirmando que en Santo Tomás sí es posible conocer-comprender auténticamente a Dios, al alma y al mundo, a través de la contemplación de la realidad mediante la razón, en la que esta actúa recibiendo-captando la verdad de las cosas y abriéndose, asimismo, al entendimiento de otra acción que aparece en ella, a saber la acción de Dios consumada en la revelación del Verbo encarnado. De igual modo, el método y la posibilidad de la metafísica, así como de la identidad - afirmación - 'beata' de la persona, radican en el esfuerzo de la razón existencial-relacional, y de la experiencia humana completa, por abrirse a la promesa y consumación que ofrece la verdad de la fe testimoniada en Jesucristo, verdadero Dios y verdadero hombre. $\mathrm{Y}$ es en este rostro y existencia histórica divina en el que se observa y contempla claramente la acción de Dios y la acción humana plena, como signo de felicidad consumada y anticipo de eternidad. La vida y el amor de Dios en su Hijo, implican esa instancia sublime, misteriosa e inefable de encuentro entre la acción de Dios y del hombre, hecha historia de Salvación. 


\section{Rodeo poético-filosófico y recapitulación final}

Diodoro Sículo refiere la historia de un dios despedazado y disperso. ¿Quién, al andar por el crepúsculo o al trazar una fecha de su pasado, no sintió alguna vez que se había perdido una cosa infinita?

Los hombres han perdido una cara, una cara irrecuperable, y todos querrían ser aquel peregrino [...] que en Roma ve el sudario de la Verónica y murmura con fe: “Jesucristo, Dios mío, Dios verdadero, ¿así era, pues, tu cara?".

[...] Pablo la vio como una luz que lo derribó; Juan, como el sol cuando resplandece en su fuerza; Teresa de Jesús, muchas veces, bañada en luz tranquila, y no pudo jamás precisar el color de los ojos.

Perdimos esos rasgos, como puede perderse un número mágico, hecho de cifras habituales; como se pierde para siempre una imagen en el calidoscopio. Podemos verlos e ignorarlos. El perfil de un judío en el subterráneo es tal vez el de Cristo; las manos que nos dan unas monedas en una ventanilla tal vez repiten las que unos soldados, un día, clavaron en la cruz.

Tal vez un rasgo de la cara crucificada acecha en cada espejo; tal vez la cara se murió, se borró, para que Dios sea todos.

Quién sabe si esta noche no la veremos en los laberintos del sueño y no lo sabremos mañana.

Jorge Luis Borges

El escritor argentino Jorge Luis Borges, en su constante búsqueda de Dios, nos sugiere e incita a reflexionar en torno a nuestra experiencia contemporánea de la Presencia Divina. Este poeta trata, como en el poema, de encontrar el anhelado rostro Divino - encarnado, presente, en acto - en todos los rincones del orbe, a través de sonetos, de metáforas y de su pregunta por la nada. El desafío más concreto y urgente, entonces, reside en cómo recuperar aquello perdido a los ojos del escritor. ¿Cómo reencontrar el rostro olvidado de Cristo, Dios y Hombre verdadero? ¿Cómo, cuándo, dónde hallar en lo cotidiano esa luz, esa fuerza, ese 
resplandor? ¿De qué manera evitar que siga muriendo [...]? Si “se evita que Dios muera" podrá también volver a vivir el hombre; este podrá salir del inmanente y adormecido laberinto de hierro que ha construido solo si se reencuentra con ese rostro, el único activo y potente, que adviene como acontecimiento presente, y que puede salvar y dar sentido a toda acción y padecimiento humanos.

Hemos dejado trazado la observación de que Dios gobierna, permanece y actúa en las cosas así como en la voluntad humana inclinándola interiormente, obrando en lo más íntimo de todas las cosas por ser la causa en cuanto fin y por ser donación y conservación de las formas y las potencias de la realidad (cf. Santo Tomás, 2001, I, C.105 a.4). Sugerimos, por consiguiente, como respuesta al desafío planteado por Borges, una experiencia cotidiana, clara y concreta de Dios, ya que Él también actúa sobrenaturalmente mediante los signos milagrosos ${ }^{14}$ de su Hijo, que aún hoy continúan siendo extraordinarios:

Volví la cara hacia el interior de la habitación y me quedé petrificado. Allí estaba Él. Yo no lo veía, yo no lo oía, yo no lo tocaba. Pero Él estaba allí. [...] Yo no veía nada, no oía nada, no tocaba nada. No tenía la menor sensación. Pero Él estaba allí. Yo permanecía inmóvil, agarrotado por la emoción. Y le percibía; percibía su presencia con la misma claridad con que percibo el papel en que estoy escribiendo y las letras [...] que estoy trazando. [...] Le percibía allí presente, con entera claridad. (García Morente, 1996, p. 42)

Asumiendo por un lado, entonces, la herencia teórico-conceptual moderna y tardo-moderna descrita y, por otro, estas lábiles y desesperadas, por momentos, búsquedas de experiencias de Dios a través de 'silenciosos gritos', como aparecían reflejadas en el relato de Borges, nuestra apuesta se resume en tres puntos:

1. Recuperar la realidad como medida del conocimiento, y como vía y criterio gnoseológico-metafísico, sin por ello pretender vivir en un contexto histórico-cultural premoderno de reflexión.

2. Recobrar, con un vínculo y diálogo con lo anterior, la realidad humana como vía racional receptivo-pasivo-activa de acceso a la realidad, y como ser consciente capaz de afirmarse y de reconocer en sí aquella exigencia trascendente o huella de Dios en él, que lo abre a no contentarse

14 "Pero milagro viene a equivaler a lleno de admiración, es decir, lo que tiene una causa oculta en absoluto y para todos. Esta causa es Dios. Por lo tanto, se llaman milagros aquellas cosas que son hechas por Dios fuera del orden de las causas conocidas para nosotros" (Santo Tomás, 2001, I, C.105 a.7.) 
total y acabadamente con nada mundano, elevando y arrojándolo así a la necesidad existencial de tener que optar frente a la muerte o a la vida de su acción, en cuanto método racional y supra-racional de verdad-relacional-trialógica.

3. Restaurar el mencionado 'percibir', que es espiritual, pasivo-activo, relacional-existencial e integral, que solo es posible en el silencio del alma, así como en la búsqueda incansable del fundamento y de la propia identidad. Gracias a los derroteros que la modernidad legó, hoy se alza en nuestro horizonte esta oportunidad positiva, esperanzadora y única de comprender-percibir, de escuchar y sobre todo de crecer en humanidad. Esto no solo ocurrirá a través de la ciencia-técnica, ni de autorealizaciones hedonistas inmanentes y pasajeras, ni mediante ídolos políticos o gnosticismos espirituales y vacíos, que, en el fondo, siguen siendo la hybris que puja por enajenar una y otra vez al hombre.

En suma, se podría abordar una percepción auténtica de Dios gracias al retorno de una fiel y adecuada percepción de la realidad, así como de la humanidad del propio ser personal y en él la posibilidad de buscar la verdad, en cuanto relación trialógica, que permita, asimismo, reconocer la dimensión trascendente, que mediante una experiencia existencial integral solo puede ser alcanzada por un rostro infinito de amor.

Por lo tanto, es hora de volver a religarnos entre todos por medio de actos pequeños, pero surgidos de una misma experiencia genuina y honda de trascendencia. Según Teilhard de Chardin, en efecto:

[...] ¿cuál es el camino que hemos tomado hasta aquí para unificarnos? Una situación material que defender. Un nuevo dominio industrial que abrir. Mejores condiciones para una clase social o para unas naciones desfavorecidas [...] He aquí los únicos y mediocres ámbitos a través de los cuales hemos todavía tratado de acercarnos. [...] Solo el amor, por la buena razón que solo él toma y junta a los seres por el fondo de ellos mismos, es capaz - este es un hecho de la experiencia cotidiana-, de dar cumplimiento a los seres, en cuanto seres, al reunirlos. (Teilhard de Chardin, 1955, p. 295; énfasis mío). 


\section{Referencias}

Agamben, G. (2005, octubre 12). ¿Qué es un dispositivo?. Conferencia. Universidad Nacional de La Plata.

Aubenque, P. (1966). Le probleme de l'etre chez Aristote: essai sur la problématique Aristotelicienne. Paris: Presses Universitaires de France.

Blondel, M. (1893/1973). L'Action. Essai d'une critique de la vie et d'une science de la pratique. Paris: Presses Universitaires de France.

Borges, J.L. (1996). Obras Completas (tomo II). Barcelona: Emecé.

Foucault, M. (1990). ¿Qué es un autor? México: Universidad Autónoma de Tlaxcala.

García Morente, M. (1996). El hecho extraordinario. Madrid: RIALP.

Gilson, E.H. (1935). Le réalisme méthodique. Paris: Éd. Chez Pierre Téqui.

Gilson, E.H. (1960). Le philosophe et la théologie. Paris: Librairie Arthème Fayard.

Jörgensen, J. (1924). Santa Catalina de Siena. Madrid: Ed. Voluntad.

Molteni, A. (Comp.). (2009). Fe y razón. Material no publicado.

Ricoeur, P. (1960). Philosophie de la volonté 2: Finitude et culpabilité. Paris: Aubier.

Ricoeur, P. (1986a). Du texte à l'action. Paris: Seuil.

Ricoeur, P. (1950/1986b). Lo voluntario y lo involuntario (J.C. Gorlier, Trad.). Buenos Aires: Docencia.

Ricoeur, P. (1994). Fe y filosofía: Problemas del lenguaje religioso. Buenos Aires: Almagesto - Docencia.

Ruiz de la peña, J. L. (1993). Creación, gracia, salvación. Santander: Sal Terrae.

Santo Tomás. (1996). De Veritate (H. Giannini y Ó. Velásquez, Trad.). Santiago de Chile: Ed. Universitaria.

Santo Tomás. (2001). Suma de Teología. Madrid: BAC.

Teilhard de Chardin, P. (1955). Le phénomène humain. Paris: Éd. du Seuil.

Tell, M.B. (2003). La Acción como «Alternativa» y «Opción». Sedes Sapientiae, VI(6), 45-52.

Tell, M.B. (2008). La constitución del sujeto ético-político en Paul Ricoeur. En J. de Zan y F. Bahr (eds.). Los sujetos de lo político en la filosofía moderna y contemporánea (169184). Buenos Aires: Universidad Nacional de San Martín. 